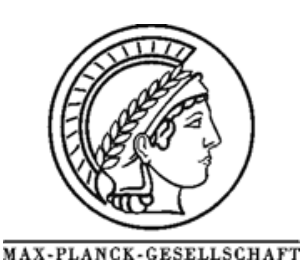

\title{
The role of carbon species in heterogeneous catalytic processes: An in-situ soft X-ray photoelectron spectroscopy study
}

\author{
E. M. Vass, M. Hävecker, S. Zafeiratos, D. Teschner, A. Knop-Gericke*, R. Schlögl \\ Fritz-Haber-Institut der MPG, Faradayweg 4-6, 14195 Berlin, Germany \\ *Corresponding author: e-mail knop@fhi-berlin.mpg.de,
}

Print publication: Issue 18 (7 May 2008) Received 15 October 2007, in final form 2 January 2008 Published 17 April 2008

\begin{abstract}
High pressure X-ray photoelectron spectroscopy (XPS) is used to characterize heterogeneous catalytic processes. The success of the new technique based on the possibility to correlate the catalytic activity and the electronic structure of an active surface. The dynamic character of a catalyst surface can be demonstrated impressively by this technique. In this contribution the basics of high pressure XPS will be discussed. Three examples of heterogeneous catalytic reactions are presented in this contribution. The selective hydrogenation of 1-pentyne over Pd based catalysts and the dehydrogenation of n-butane and the oxidation of ethylene over $\mathrm{V}$ based catalysts.

It is shown, that the formation of subsurface carbons plays an important role in all the examples. The incorporated carbon changes the electronic structure of the surface and so controls the selectivity of the reaction. A change of the educts in the reaction atmosphere induces modifications of the electronic surface structure of the operation catalysts.
\end{abstract}

Keywords: high pressure XPS, heterogeneous catalysis, selective hydrogenation of 1-pentyne, dehydrogenation of n-butane, selective ethylene oxidation

\section{Introduction}

Obviously, the understanding of the interaction of a catalysts surface with the reactants plays a key role in a detailed description of catalytic processes. However, a spectroscopic characterisation of the reacting surface under ambient conditions is challenging. While photon-in photonout techniques can be applied at high gas pressures, they typically show a lack of surface sensitivity. Photon-in electron-out techniques like XPS on the other hand are intrinsically more surface sensitive due to the strong interaction of (low energetic) electrons with matter but they suffer, for the same reason, by limitations in the pressure of the ambient gas due to the strong scattering of the outgoing electron in the gas phase. Thus, XPS has been typically applied only under UHV or HV conditions, i.e. far away from normal operation conditions of a catalyst.

Nevertheless, recent methodological developments [1-7] make it feasible to expand the operation range of XPS by several magnitudes in pressure from UHV conditions to ambient pressure in the mbar range. The use of XPS as a tool for characterization of catalysts is attractive for several obvious reasons. XPS shows a universal chemical sensitivity by probing the different core levels of the elements. It can detect all elements except for hydrogen in all their different electronic states, e.g. XPS is not limited to certain specific valences of an element. The surface sensitivity of XPS critically depends on the kinetic energy of the released photoelectrons and thus on the energy difference between the incoming photon and the binding energy of the core level. Low energetic electrons of $50-150 \mathrm{eV}$ show the smallest inelastic mean free path (IMPF) in a solid and thus the highest surface sensitivity [8]. Thus, XPS develops into an ultimate surface sensitive tool to characterize the topmost layers of a material when it is operated with a tuneable X-ray source at a storage ring. Synchrotron based XPS makes it feasible to ensure a low kinetic energy of the released photoelectrons for all core levels. To exemplify this 
fact it is useful consider that the IMFP e.g. in $\mathrm{V}_{2} \mathrm{O}_{5}$ for $\mathrm{V} 2 \mathrm{p}$ photoelectrons is $17.7 \AA$ when excited with $\mathrm{Mg} \mathrm{K} \alpha$ radiation (i.e. a standard $\mathrm{X}$-ray tube, $\mathrm{h} v=1253.4 \mathrm{eV}$ ) and just $6.6 \AA$ when the kinetic energy of the electrons is $150 \mathrm{eV}$ (i.e. $\mathrm{h} v=670 \mathrm{eV})$. Excitation of the $\mathrm{C} 1 \mathrm{~s}$ core level in a carbon matrix results in an IMFP of $28 \AA$ and $8.6 \AA$ for $h v=1253.4$ $\mathrm{eV}$ and $\mathrm{h} v=330 \mathrm{eV}$, respectively (values calculated according to the Penn et al. algorithm TPP-2m [8]). In addition, the element sensitivity is increased due to the enhancement of the ionization cross section at excitation energies close to the threshold: $\mathrm{V} 2 \mathrm{p} 0.2 \mathrm{Mb}$ for $\mathrm{hv}=1253 \mathrm{eV}$ versus $1 \mathrm{Mb}$ for $h v=670 \mathrm{eV}, \mathrm{C} 1 \mathrm{~s}: 0.02 \mathrm{Mb}$ for $\mathrm{hv}=1253 \mathrm{eV}$ versus $0.6 \mathrm{Mb}$ for $\mathrm{hv}=330 \mathrm{eV}$ [9].

Synchrotron based XPS allows also for specific modes of depth resolution when the same core level is investigated with varying photon energies resulting in different kinetic energies of the photoelectron, i.e. different information depths for the same element. Thus, there is a smart way of "element depth profiling" without destruction of the surface. While direct interaction of the reactants with the catalyst takes place only on the outermost surface layer (of inner or outer surfaces), species in deeper surface layers ("subsurface") often play an important role in modifying the electronic structure on the outermost surface and thus creating active sites for adsorption or reaction. Furthermore, subsurface species might play a role as a reservoir for surface species, as well. Examples will be given in this report.

In addition, synchrotron based XPS shows a superior energy resolution compared to XPS based on standard (i.e. non-monochromatic) laboratory X-ray tubes due to the small bandwidth of the excitation source.

The use of synchrotron radiation facilities allows investigation of the effect of the morphology of layers on shift and broadening of XPS lines, due to high energy resolution and tuneable photon energy. It is well known that there is an effect of the layer thickness on the FWHM and on the energy position of XPS lines. Himpsel et al have shown that the oxidation state of $\mathrm{Si}$ in a $14 \AA$ thick Siliconoxide layer grown on $\operatorname{Si}(111)$ changes as a function of the photon energy [10]. In this study different photon energies were used to measure the $\mathrm{Si} 2 \mathrm{p}_{3 / 2}$ core level of the oxide layer. With photon energy of $130 \mathrm{eV}$ it was observed that the $\mathrm{Si}^{3+}$ contribution is enhanced relative to $\mathrm{Si}^{1+}$ and $\mathrm{Si}^{2+}$ contributions [10]. The authors declare this effect partly by the location of the $\mathrm{Si}^{3+}$ species closer to the surface and therefore the corresponding XPS signal is more pronounced at $130 \mathrm{eV}$ compared to more bulk sensitive measurement with $400 \mathrm{eV}$ [10]. Thus the FWHM of a XPS line, which might be the envelope curve of several different oxidation states changes as a function of layer thickness and therefore changes with the morphology. Since the binding energy of different oxidation states might be different as well shifts in the energy position of XPS lines might be observed. These arguments are not only valid for oxides. In general shifts and changes in the broadening of XPS lines will be expected in all system showing inhomogeneities of the chemical bonding in the layer or particle as a function of thickness and size, respectively.

There exist although artifical effects on the shift and broadening of XPS lines. Charging of the investigated sample influences at least the energy position of the XPS line. In the case of inhomogeneous charging the FWHM of the XPS lines might be enhanced as well. Charging might be reduced in gas atmospheres, because the ionization of gas phase molecules due to absorption processes in the gas phase creates charge, which compensates partly charging of the sample.

Another point that will be highlighted in this report is the importance of chemical complexity. Certainly, "simple" model systems are necessary to gain deeper insight into elementary steps of catalytic reactions (i.e. oxygen activation). Working at reduced temperatures and pressures are extremely useful to eventually slow down processes. But to evaluate without assumptions if the species found are indeed involved in the reaction is only possible with the real material under relevant conditions. The examples presented in this article clearly show, that in situ XPS can be not only applied to model systems but also to real supported catalysts. Since the support of real catalyst is usually an isolating material like alumina, silica, titania, etc., special care has to be taken for the calibration of the binding energy scale in the case of charging.

This immediately raises the question: What are relevant conditions? Most of the reactions that are studied by in situ XPS take place at different (i.e. higher) pressure when tested in a reactor (normal operation conditions). Thus, it needs to be proven that the catalyst surface at the conditions applied for the spectroscopic characterization acts in the same way as under normal operation conditions. Macroscopically, this is reflected in the conversion of the feed gas into the different products in catalysis. This implies: A) the products need to be determined during the spectroscopic investigation; B) it is highly advantageous if the chemical reaction under investigation allows for different reaction pathways so that the branching ratio (i.e. the selectivity) might be evaluated. This branching ratio might serve as a macroscopic fingerprint of the surface state. If a reaction under normal operation conditions can be mimicked in the above mentioned way, the actual reaction parameters (e.g. pressure, mixing ration of reactants, temperature) might be chosen differently to the normal operation conditions without corrupting the relevance of the obtained results. Thereby, meaningful relationships between the electronic structure and the functionality of the material can be obtained ("structure-activity-relationship").

To clarify and to demonstrate the points mentioned in the introduction, three examples will be discussed in the following. All of them elucidate the role of carbon species on the surface of the catalysts.

A study of Pd based catalysts used in selective hydrogenation of 1-pentyne will highlight the role of carbon deposits and carbon subsurface layers on the selectivity of the reaction. The $2^{\text {nd }}$ section, closely related to the previous section, studies the oxidation of ethylene on $\operatorname{Pd}(111)$ single 
1a)

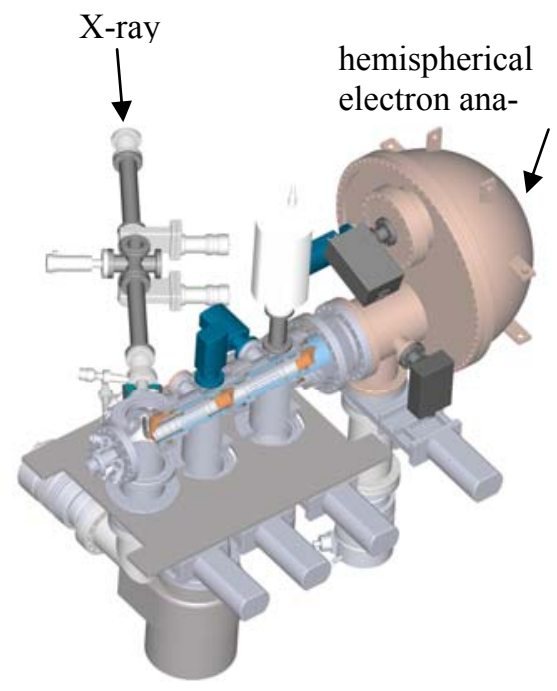

1b)

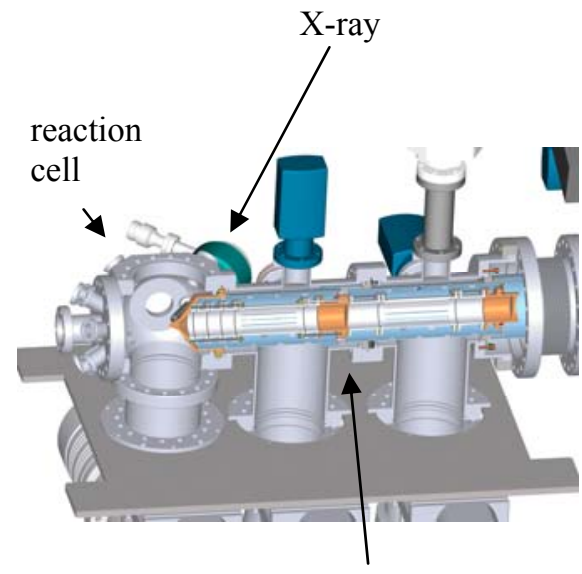

electrostatic lens system

Fig. 1: Schematic layout of the high pressure XPS system. In b) a detailed sketch of the reaction cell and the electrostatic lens system is shown.

crystal. Similarities between the two reactions catalysts by Pd based materials will be pointed out.

Finally, in the $3^{\text {rd }}$ example V-based catalyst in the dehydrogenation of $n$-butane will be described in detail. In that case $\mathrm{C}$ deposits block the surface and deactivate the catalyst at low temperatures. Strategies to avoid the activity loss due to coking and their impact on the catalysts electronic structure are discussed.

\section{Experimental}

The experiments have been performed at the synchrotron radiation facility BESSY (Berliner Elektronenspeicherringgesellschaft für Synchrotronstrahlung) located in Berlin using the high brilliance radiation of the undulator U49/2 as an X-ray source [11-13]. In situ XP spectra were obtained using the high pressure XPS station designed and constructed at the FHI. Details of the set-up are described elsewhere [7]. A sketch of the set-up and a close -up of the experimental cell and the differentially pumped electrostatic lens system is shown in Figure 1a and Figure 1b.

In brief, the samples (e.g. single crystals, polycrystalline foils, pressed powders) are mounted inside a reaction cell onto a sapphire sample holder approx. $2 \mathrm{~mm}$ in front of the $1^{\text {st }}$ aperture of a differentially pumped electrostatic lens system. The homebuilt electron lens serves as the input system for a (modified) commercial hemispherical electron analyzer (PHOIBOS 150, Specs-GmbH). X-rays enter at $55^{\circ}$ relative to the electron analyser axis. A variety of gases can be introduced to the cell and the gas phase composition is monitored via mass spectrometer simultaneously to the spectroscopic characterization by XPS. Heating is provided by a NIR laser at the rear of the sample and monitored by a thermocouple attached directly to the sample surface.

\section{Case studies}

\subsection{1-Pentyne Hydrogenation on Pd based cata- lysts}

In this part the influence of $\mathrm{C}$ deposit on Pd base catalysts used in selective 1-pentyne hydrogenation on the catalytic performance will be discussed. The formation of a surface/subsurface Pd-C phase is observed. A similar phase is observed in the case of the ethylene oxidation over Pd as described in section 3.2. In both cases, the subsurface $\mathrm{C}$ layer influences the selectivity of the reaction.

The influence on the catalytic properties of carbon residing in the subsurface region was described previously [14-16]. Since these are all ex situ studies the question of stability of intermediates is an issue. Most of these species are metastable and form only under reaction conditions. It was shown experimentally that the adsorbed $\mathrm{C}$ atom has to pass activation barriers of $107 \mathrm{KJ} / \mathrm{mol}$ to pass the surface Pd layer [17]. DFT calculations revealed an activation energy of $59-78 \mathrm{KJ} / \mathrm{mol}[18]$. The $\mathrm{C}$ atoms then become energetically stabilized in the subsurface bulk dissolved state, whereas the $\mathrm{C}$ migration inside the Pd bulk has an considerably lower activation barrier at $65 \mathrm{KJ} / \mathrm{mol}$ [19]. The amount of carbon within the first atomic layer will depend strongly on temperature, pressure and time. A UHV study allowed quantification of the carbon uptake from ethane dissociation through the surface Pd layer [17]. But in this investigation it was not possible to measure the distribution of carbon among near-surface and deeper bulk regions. In situ X-ray photoelectron spectroscopy using tunable syn 
Table 1: Conversion and selectivities in 1-pentyene hydrogenation over various catalysts at 0.9 mbar conditions at $358 \mathrm{~K}$.

$5 \% \mathrm{Pd} / \mathrm{CNT} \quad 3 \% \mathrm{Pd} / \mathrm{Al}_{2} \mathrm{O}_{3} \quad \mathrm{Pd}$ foil $\quad \mathrm{Pd}(111)$

\begin{tabular}{lcccc}
\hline Conversion (\%) & 10 & 5 & 2.5 & $<1$ \\
Selectivity pentene (\%) & 95 & 80 & 98 & 100 \\
Selectivity pentane (\%) & 5 & 20 & 2 & -
\end{tabular}
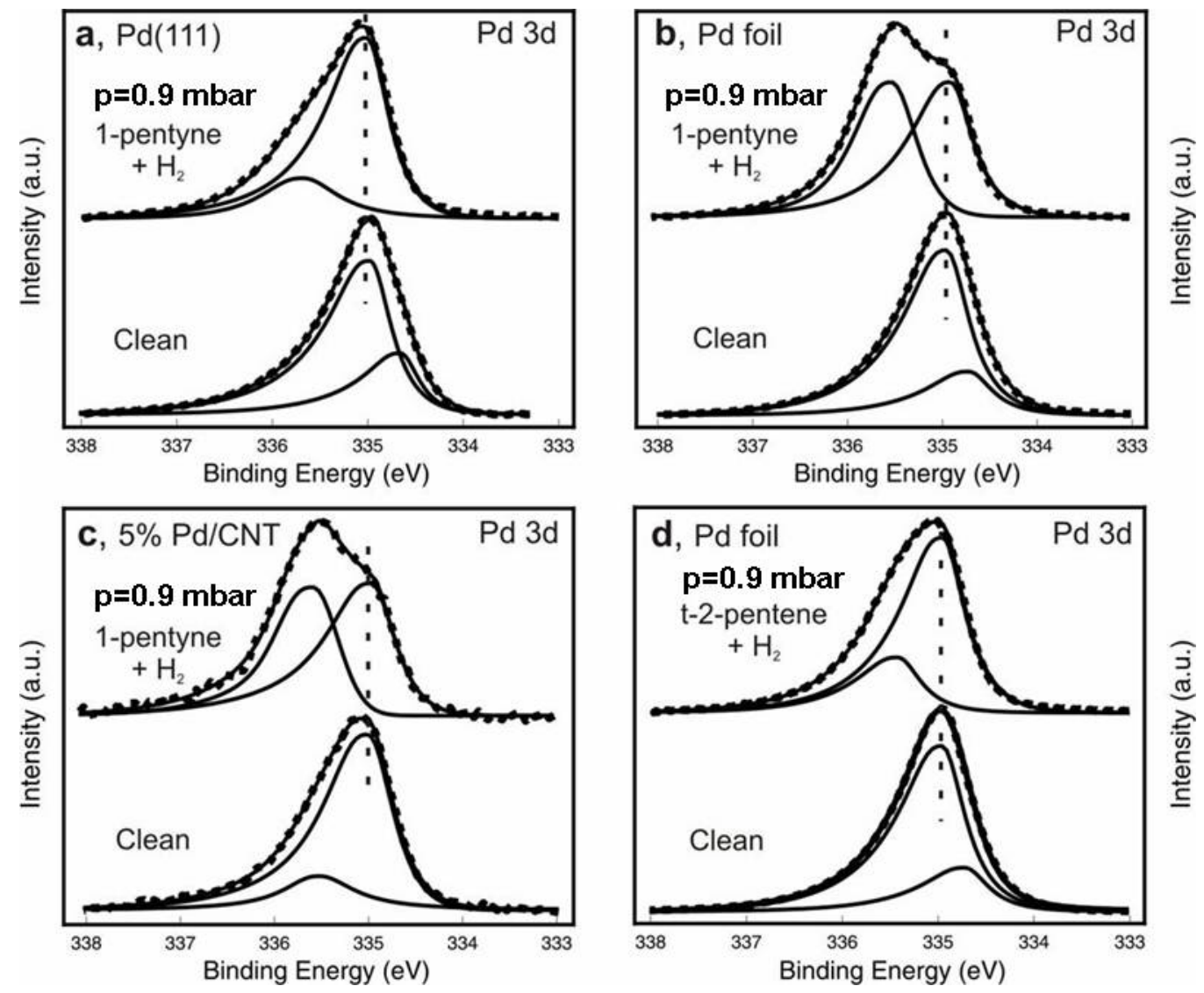

Fig. 2: $\mathrm{Pd} 3 \mathrm{~d}_{5 / 2}$ of a) $\mathrm{Pd}(111)$, b) $\mathrm{Pd}$ foil, c) $5 \% \mathrm{Pd} / \mathrm{CNT}$ in the reaction mixture of $0.85 \mathrm{mbar}_{2}+0.05$ mbar 1 -pentyne at $358 \mathrm{~K}$. The incident photon energy was $720 \mathrm{eV}$. Dashed line: measured data, full line: fits. As a comparison, Pd3d of Pd foil during the hydrogenation of trans-2pentene $\left(0.2 \mathrm{mbar}\right.$ trans-2-pentene $\left.+0.6 \mathrm{H}_{2}\right)$ is shown in (d). [20]

chrotron light can be used to monitor the concentration profile of involved species perpendicular to the surface as described in the introduction.

Four different catalysts have been investigated by in situ XPS under selective hydrogenation reaction conditions (0.85 mbar $\mathrm{H}_{2}+0.05$ mbar 1-pentyne at $\left.358 \mathrm{~K}\right)$ of 1 pentyne [20]. All samples showed catalytic activity in the hydrogenation of 1-pentyne in the mbar pressure range as shown in Tab.1. Pd(111) produces only pentene, whereas the other catalysts form products related to single and total hydrogenation.

Figure 2 shows the $\mathrm{Pd} 3 \mathrm{~d}_{5 / 2}$ core level spectra of a) $\mathrm{Pd}(111)$, b) $\mathrm{Pd}$ foil, and c) $5 \% \mathrm{Pd} / \mathrm{CNT}$ in the reaction mixture. For comparison the $\mathrm{Pd} 3 \mathrm{~d}_{5 / 2}$ core level of a Pd foil in 0.2 mbar trans-2-pentene +0.6 mbar $_{2}$ ) is shown. Carbonaceous adsorbed species induced a shift of the surface core levels to higher binding energy (BE) of $335.7 \mathrm{eV}$ compared to the bulk palladium signal $(\sim 335.0 \mathrm{eV})[21]$. The structure at $334.7 \mathrm{eV}$ in the spectra of the clean $\mathrm{Pd}$ (111) and foil surfaces is due to the surface core level shift [20]. The Pd foil and the supported catalyst show at $335.6 \mathrm{eV}$ a palladium peak with significantly higher intensity compared to Pd (111). In the hydrogenation of trans-2-pentene on Pd foil this intense new component at $335.6 \mathrm{eV}$ did not form, only adsorbates induced states at $335.7 \mathrm{eV}$ formed. The valence band spectra (not shown) of a Pd foil taken during hydrogenation of 1-pentyene show a redistribution of the spectral weight in the valence band. The intensity of higher lying levels of the Pd d- band decreased while a new band at $6 \mathrm{eV}$ developed [20] . 


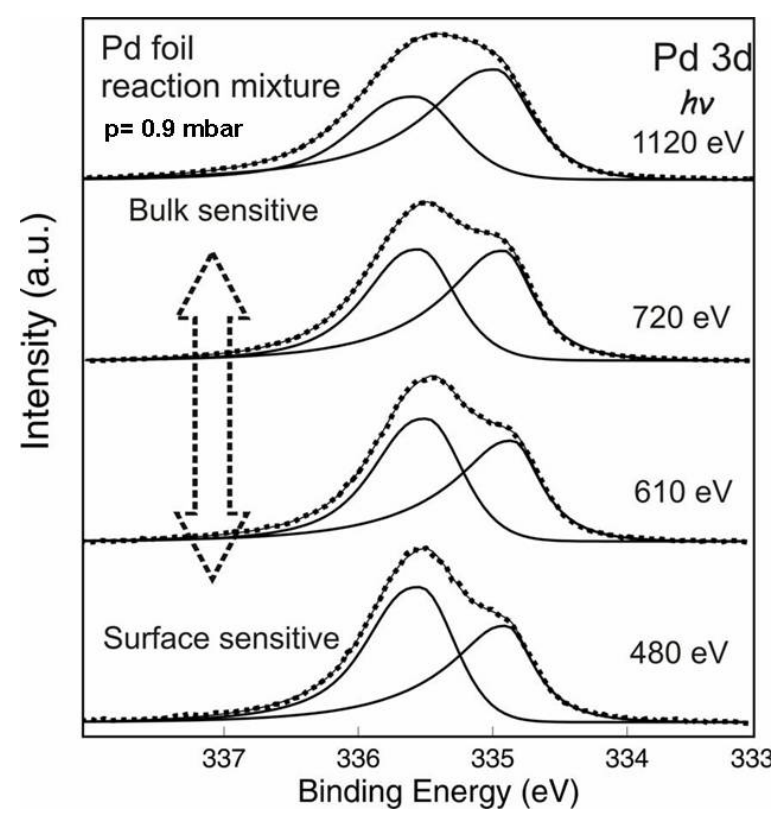

Fig. 3: Nondestructive depth profile experiment on $P d 3 d_{5 / 2}$ core level of Pd foil during 1-pentyne hydrogenation $\left(0.85 \mathrm{mbar}_{2}+\right.$ 0.05 mbar 1-pentyne at $358 \mathrm{~K}$ ).

[20]

Figure. 3 shows XP spectra of a Pd foil under reaction conditions using different photon energies and thus different information depths. From this figure the authors concluded that the component at $335.6 \mathrm{eV}$, is located on the outermost Pd surface layers. The formation of a $\beta$-hydride can be exclude since it's BE is given by $335.2 \mathrm{eV}$ in [22]. A simple calculation allows the authors to conclude, that the new component has a thickness of 2-3 Pd atomic layers. The calculation showed as well, that there is not only a carbon layer on top of the Pd foil. Therefore this component was assigned to a Pd state modified by dissolved $\mathrm{C}$ in the top few layers.

The change of the electronic structure of the catalysts is related to changes in the geometric structure. High resolution TEM pictures have indicated, the Pd lattice fringes near the surface being expanded by a few percent in comparison with Pd bulk values [23].

The carbon phase was investigated in detail by in situ XPS. These measurements demonstrate the metastable character of the Pd-C phase, since this phase partly decomposed in the absence of 1-pentyne gas-phase above the sample surface.

The C1s spectrum during reaction (curve 1 in figure. 4a) shows a maximum at $284.6 \mathrm{eV}$ with a shoulder at 283.4 $\mathrm{eV}$. The latter BE is close to that of carbides [21]. As the 1pentyne is switched off the low BE shoulder disappears and the intensity of the main peak decreases resulting in a shift of the peak to $284.4 \mathrm{eV}$ (curve 2). It is remarkable, that the time constants of the two reduction processes are different. The main peak loses intensity instantaneously, whereas the shoulder at lower binding energies disappeared after several minutes. This is a clear indication, that the two peaks are due to two discrete species, which are not directly a)

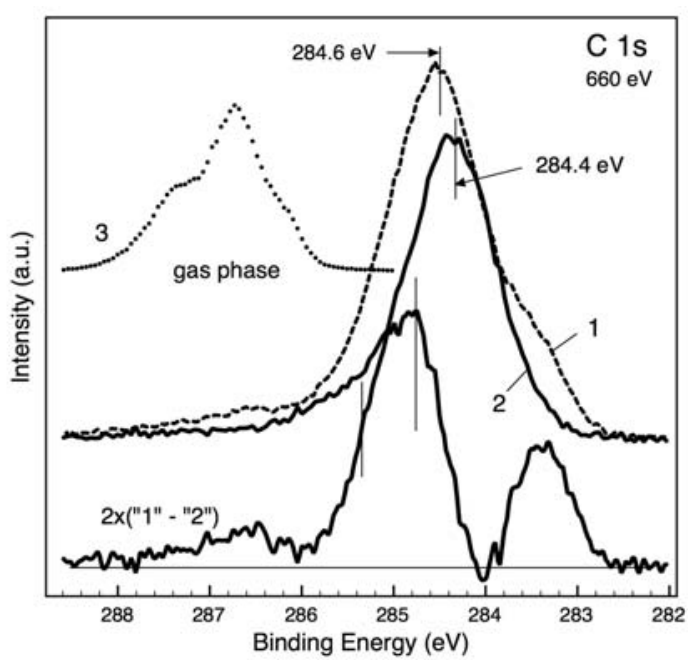

b)

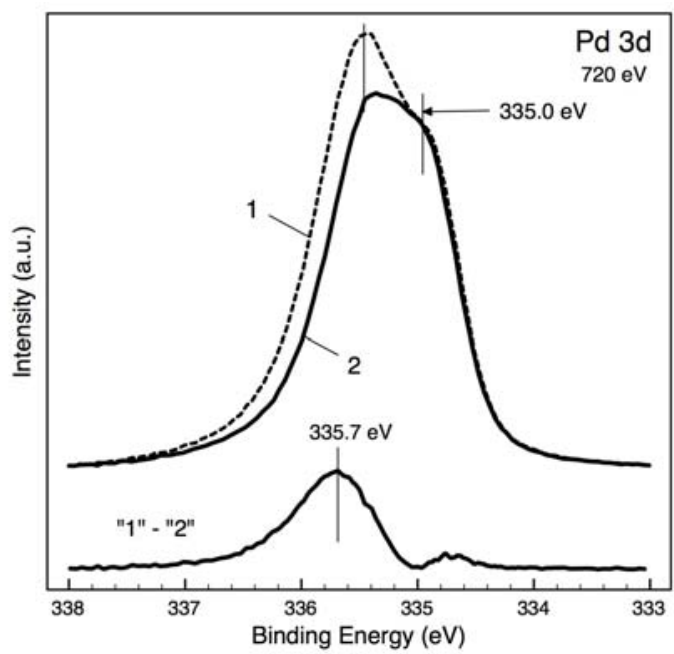

Fig. 4: a) C1s and b) Pd3d region of Pd foil at different conditions. 1 : in the reaction mixture; 2 : after switching off 1-pentyne (only $\mathrm{H}_{2}$ ) 3: after switching off $\mathrm{H}_{2}$ (only 1-pentyne). All spectra were recorded at $358 \mathrm{~K}$. Some different spectra are also shown [20].

related. The difference spectrum (curve 1-2) in Figure.4a shows an asymmetry of the peak at $284.8 \mathrm{eV}$. The peak can be fitted with two profiles at $284.8 \mathrm{eV}$ and $285.2 \mathrm{eV}$ (not shown). Since the gas phase does not contribute within this energy range as shown by curve 4 in Figure.4a, the two peaks are attributed to chemisorbed pentyne molecules on $\mathrm{Pd}$, which desorbed as the pentyne feed is switched off. The switch-off-experiments have shown, that pentyne is adsorbed on the Pd-C phase.

The corresponding Pd3d spectra to the above discussed $\mathrm{C} 1 \mathrm{~s}$ spectra are shown in figure. $4 \mathrm{~b}$. As the pentyne is switched off, the peak assigned to the Pd-C component is partially decreased. Since the difference indicates a binding energy of $335.7 \mathrm{eV}$ the $\mathrm{Pd}-\mathrm{C}$ phase may be the sum of more than one component.

The reaction profile obtained in a closed loop reaction at constant 1-pentyne pressure of 10 Torr is shown in 

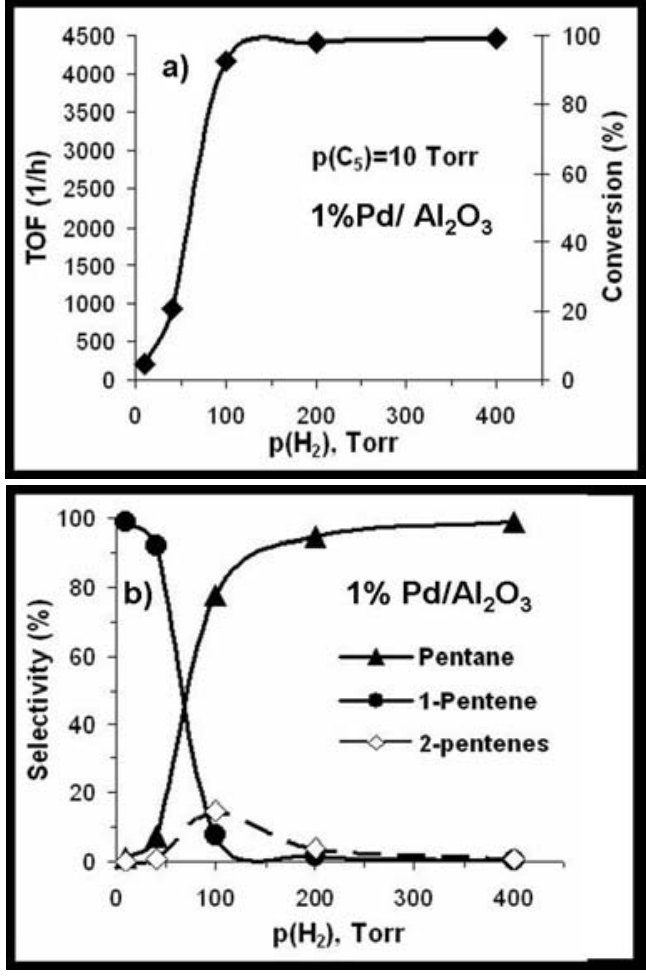

Fig. 5: 1-Pentyne hydrogenation over $1 \% \mathrm{Pd} / \mathrm{Al}_{2} \mathrm{O}_{3}$ in a closed loop-reactor. The partial pressure of 1-pentyne was 10 Torr. a) conversion, b) selectivity [20]

Figure. 5. Two different selectivity regimes can be identified. At low hydrogen partial pressures and low $\mathrm{H}_{2}$ : $\mathrm{C}_{5}$ ratios the hydrogenation is selective, since 1-pentene was formed as the major product. At $\mathrm{H}_{2}: \mathrm{C}_{5}$ ratios grater than 7 the activity was significantly enhanced. Nearly full conversion was observed and the selectivity changed to total hydrogenation.

Many results on the chemistry of subsurface and bulk dissolved hydrogen have been published within the last years. [24-27]. Thermal desorption spectroscopy measurements have shown, that hydrogen emerging from the bulk of metal particles to the surface appears at lower temperature and is therefore more energetic and thus far more reactive than surface hydrogen [28]. But this hydrogen is too active to be selective. It was shown, that bulk dissolved hydrogen is active in alkene hydrogenation or in the total hydrogenation of alkynes [27, 29]. The equilibrium between surface hydrogen and dissolved hydrogen in the volume seems to be disturbed by the formation of the Pd-C surface phase, which inhibits the repopulation of the bulk-dissolved hydrogen, as well as its emergence to the surface.

The total mass change of a sample bed was measured by tapered element oscillating microbalance (TEOM). Each hour on stream the retained mass levels where estimated after purging with helium. The gas feed was 1 bar of hydrogen and 0.1 bar of 1-pentyne. To change from total hydrogenation conditions to conditions favoring the selective hydrogenation the hydrogen was diluted from $100 \%$ to $5 \%$ by helium. It turned out, that the mass uptake is a factor of five higher under selective hydrogenation conditions.

Pulses of 1-pentyne in helium were passed over $1 \%$ $\mathrm{Pd} / \mathrm{Al}_{2} \mathrm{O}_{3}$ catalyst. The catalyst was pretreated in 1 bar hydrogen at RT to saturate the amount of hydrogen diluted in the Pd particles. The product pulses were analyzed by mass spectrometry. The first product pulse contained mainly pentene and traces of pentane. Subsequent pulses did not show any conversion. The ratio of hydrogen atoms, which are required to transform the 1-pentyne to pentene and $\mathrm{Pd}$ atoms in the catalyst can be estimated to $13: 1(\mathrm{H}: \mathrm{Pd})$. This value can not be explained by dissolved $\mathrm{H}$ in Pd. Therefore the substrate must play a significant role. The support was found to be inactive in the absence of palladium, hydrogen can spill over from the metal to the support. Hence there is a hydrogen-reservoir, and the spilled over hydrogen can supply activated hydrogen for the reaction. In contrast to the bulk dissolved hydrogen observed in TDS measurements, surface hydrogen is selective.

The authors suggested a model of the Pd surface active in the selective hydrogenation on 1-pentyne shown in Figure 6. In situ XPS depth profiling showed that a Carbon diluted Palladium-surface phase was formed in the early stage of the hydrogenation, which composed of a thin layer of $\sim 3 \mathrm{Pd}$ atomic layer thickness on top of metallic palladium with additional carbon incorporated in the bulk. As pentyne is switched off, the adsorbed molecules desorb and the Pd-C layer breaks up.

Selective hydrogenation of 1-pentyne was the major reaction on this modified Pd surface, since total hydrogenation was strongly inhibited by the elimination of subsurface $\mathrm{H}$ to participate in the reaction. Further the modified surface electronic structure of Pd obviously and isolation of active sites possibly contributed to governing hydrogenation of alkynes to alkenes. Since the switch off experiments indicated the metastable character of this surface, in situ experiments are obligatory when aiming to reveal mechanistic details of heterogeneous hydrogenation chemistry.

A similar Pd-C surface species, which has a strong influence on the selectivity, was found during the oxidation of ethene on $\operatorname{Pd}(111)$. The peculiarities of this system will be described in the next example section.

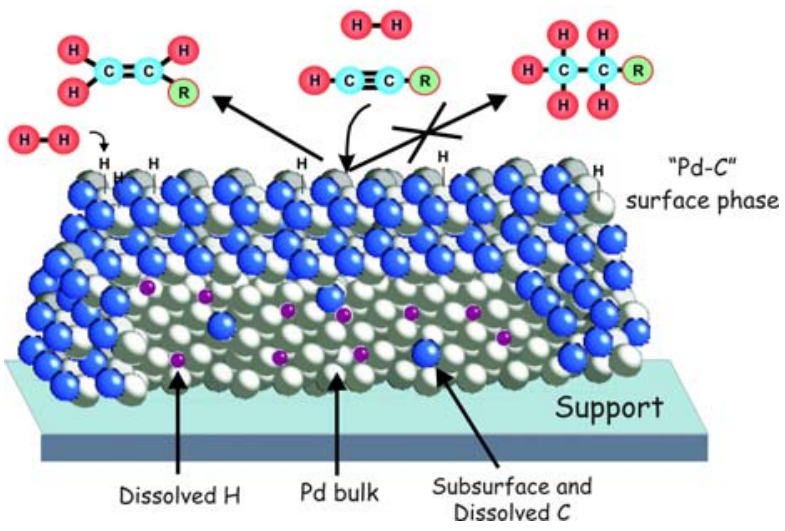

Fig. 6: Model of a palladium surface during 1-pentyne hydrogenation 
a)

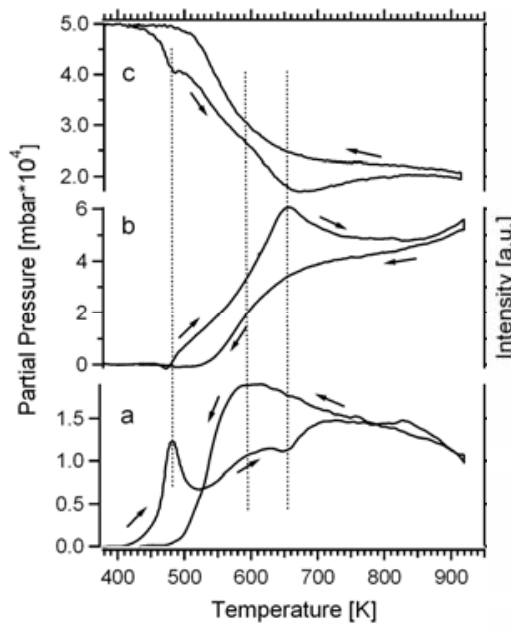

b)

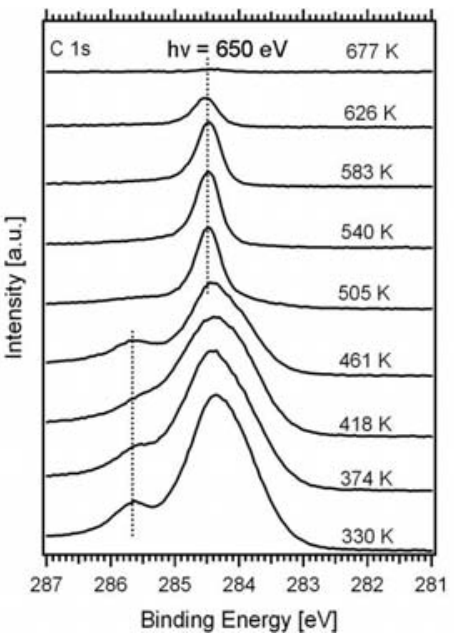

c)

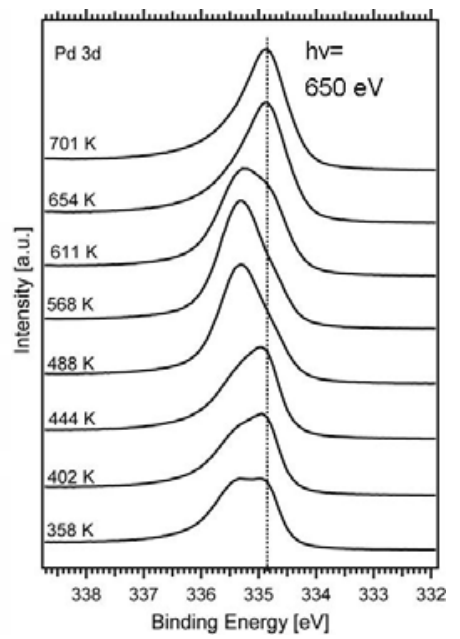

Fig. 7: a) Partial pressure of $\mathrm{a}: \mathrm{CO}_{2}, \mathrm{~b}: \mathrm{CO}$ and c:ethene during the oxidation of ethene over Pd (111) plotted against temperature. b) $\mathrm{C} 1 \mathrm{~s}$ region recorded during heating from 330 to $670 \mathrm{~K}$. c) $\mathrm{Pd} 3 \mathrm{~d}_{5 / 2}$ region recorded during heating. Photon energy for all XP spectra was $650 \mathrm{eV}$. [30]

\subsection{Ethene Oxidation on Pd based catalysts}

$\operatorname{Pd}(111)$ has been studied during the oxidation of ethene in the pressure range of $10^{-3} \mathrm{mbar}\left(5 \times 10^{-4} \mathrm{mbar}\right.$ $\mathrm{C}_{2} \mathrm{H}_{4}$ and $1.5 \times 10^{-3} \mathrm{O}_{2}$ ) at temperatures of $330-923 \mathrm{~K}$. Figure $7 \mathrm{a}$ shows the partial pressure of carbon oxide products plotted versus time. The $\mathrm{CO}$ and $\mathrm{CO}_{2}$ signals show strong hysteresis behaviour, which is a consequence of the delayed formation of the $\mathrm{Pd}-\mathrm{C}$ phase during cooling [30]. The water signal is not included since the partial pressure of water follows the inverse ethene pressure multiplied by 2.

The reaction starts at $\mathrm{T}>430 \mathrm{~K}$, which is in agreement with previous thermal ethene decomposition studies [17]. A fine structure of the initial activity is observed. A minimum of the ethene partial pressure forms at $480 \mathrm{~K}$ and the selectivity for $\mathrm{CO}_{2}$ is almost $100 \%$ since $\mathrm{CO}$ formation has not yet started. Between $480 \mathrm{~K}$ and $500 \mathrm{~K}$ the ethene conversion is constant and carbon dioxide formation rate decreases, reaching a local minimum at $520 \mathrm{~K}$, whereas the $\mathrm{CO}$ formation increases at the same temperatures. The catalyst became highly active with respect to $\mathrm{CO}$ production. The low temperature regime $(380-660 \mathrm{~K})$ is characterized by a significant activity increase and a strong decrease of $\mathrm{CO}_{2}$ selectivity and a strong increase in $\mathrm{CO}$ selectivity. At high temperatures (660 to $923 \mathrm{~K}$ ), the activity is more or less constant and the selectivity changes are less pronounced. $\mathrm{CO}$ remains the main product.

Figure $7 \mathrm{~b}$ shows the $\mathrm{C} 1 \mathrm{~s}$ photoelectron spectra during the heating of the sample. In the temperature range from $330-461 \mathrm{~K}$ the $\mathrm{Pd}(111)$ surface is covered by carbon containing surface species, indicated by a broad peak be- tween 283 and $286 \mathrm{eV}$. Binding energies between 285.53 $\mathrm{eV}$ and $285.80 \mathrm{eV}$ are given in the literature for low and high CO coverage respectively [31]. Therefore, the shoulder at $285.65 \mathrm{eV}$ is most likely due to adsorbed CO. The high width of $\mathrm{C} 1 \mathrm{~s}$ peak centered at 284.5 indicates the contribution of several carbon species, a meaningful assignment of which is not possible here. However assignment of this peak to ethylidyne adlayers should be rouled out, since ethylidyne decomposes above $350 \mathrm{~K}$ [17, 32]. Between 461 and $505 \mathrm{~K}$ the $\mathrm{C} 1 \mathrm{~s}$ spectrum changes completely. The broad peak between 283 and $285.5 \mathrm{eV}$ and the $\mathrm{CO}$ peak at $285.65 \mathrm{eV}$ disappear. Instead a sharp peak at binding energy of $284.50 \mathrm{eV}$ formed, indicating the presence of a single $\mathrm{C}$ species. The $\mathrm{BE}$ shift relative to adsorbed $\mathrm{CO}$ is in good agreement with calculations for dissolved carbon atoms [18]. This peak remains at a constant intensity up to $583 \mathrm{~K}$, then vanishes above $677 \mathrm{~K}$.

The Pd $3 \mathrm{~d}_{5 / 2}$ spectra, shown in Figure. $7 \mathrm{c}$, are characterized by a peak at $334.9 \mathrm{eV}$ assigned to the Pd bulk and a shoulder at higher binding energies in the temperature range from 358 to $444 \mathrm{~K}$. The shape of the spectra changes strongly at higher temperatures. When the CO formation starts, the peak shifts to $355.4 \mathrm{eV}$ and the peak becomes nearly symmetric. At $611 \mathrm{~K}$ the Pd bulk component contributes more strongly to the spectrum and above $654 \mathrm{~K}$ the spectrum becomes rather characteristic of clean Pd metal.

From the above described results is evident that the ethene oxidation over Pd is catalysed by two Pd phases, the metallic and an electronically altered phase, which is described by carbon dissolved in Pd subsurface/surface region. The following explanation is proposed for the higher selectivity of the Pd-C phase to $\mathrm{CO}$ formation in the low 
temperature range. Since reactive carbon atoms are ubiquitously present in the dissolved carbon state of the catalyst, the steady state coverage of adsorbed oxygen may be rather low and a reduced lifetime of $\mathrm{CO}$ on the electronically altered surface may specifically favor the $\mathrm{CO}$ desorption pathway [17].

\section{3 n-butane dehydrogenation on $V$ based cata- lysts}

Valorisation of lower alkanes through dehydrogenation is an important process due to high demand for their unsaturated equivalents, which are widely used as a feedstock for commercial products. Dehydrogenation of light alkanes is achieved by the use of chromia or platinum based catalysts supported on alumina [33, 34]. However there has been a great deal of interest in the use of vanadia based catalysts for the (oxidative) dehydrogenation of light alkanes [35-40].

A major problem of dehydrogenation catalysts is loss of activity due to coking. This occurs readily due to the high temperature and low pressure required to achieve high yields of products. The thermodynamic limitations of the reaction can be overcome by addition of oxygen to the feed (i.e. oxidative dehydrogenation). The benefits of this are
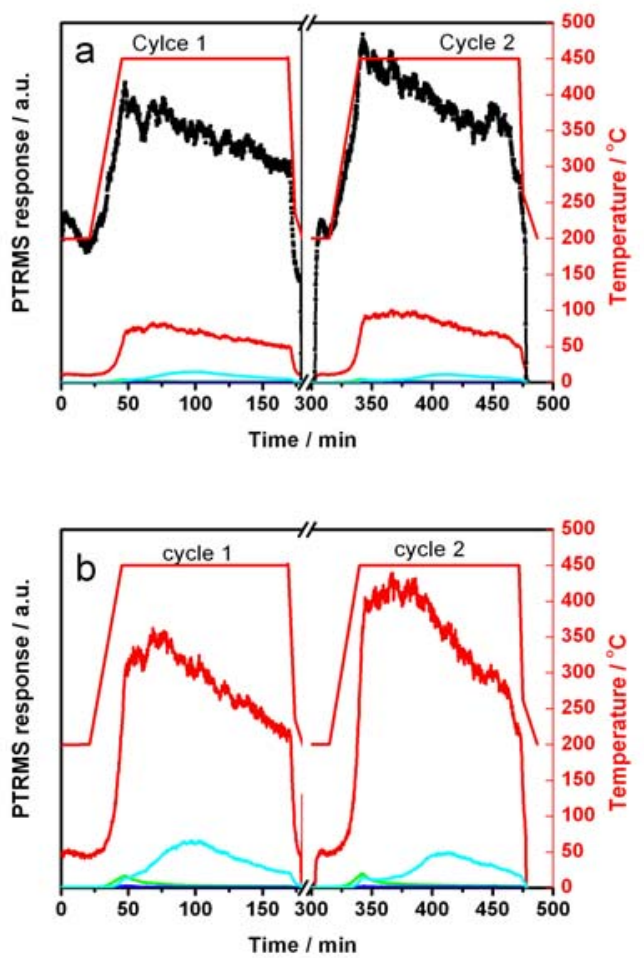

Fig. 8: Reaction profile of $8 \% \mathrm{~V} /$ alumina catalyst under dehydrogenation conditions $(0.4$ mbar $n$-butane and $723 \mathrm{~K})$ and an enlarged scale view of the low concentration products, denoted as a) and b) respectively. The products are assigned by different colours. Black: Butane, red: Butadiene, green: Furan, blue: DHF/Crotonaldehyde, cyan: Benzene. reduction in formation of coke and the ability to run the reaction at reduced temperatures. In the case of coke formation, the catalyst can be regenerated by treatment in oxygen at high temperature to remove the deposited carbon.

By the use of high-pressure in-situ XPS we have been able to probe the surface of a series of $\mathrm{V}_{\mathrm{x}} \mathrm{O}_{\mathrm{y}} /$ alumina catalysts (1-8 wt\% V/alumina) under dehydrogenation conditions (typically 0.4 mbar $n$-butane and $723 \mathrm{~K}$ ). Reaction products were followed by mass spectrometry. In this case a Proton Transfer Reaction Mass Spectrometer (PTRMS) and a quadrupole mass spectrometer were used to detect changes in the effluent gases while measuring spectra concurrently.

Figure 8 shows a typical reaction profile of $n$-butane dehydrogenation over $8 \mathrm{wt} \%$ V/alumina as measured by PTRMS. The major products detected were butene and butadiene (hydrogen evolution was followed by quadrapole MS). Figure $8 \mathrm{~b}$ shows an enlargement of the low concentration products, which shows the formation of oxygenated products such as furan during heating to $723 \mathrm{~K}$. As can be seen in figure 8 , the maximum in formation of benzene corresponds with a change in slope of the butadiene formation. Hence, even at low pressures deactivation of the catalyst is observed. Since deactivation occurred at much slower rate at this low pressure, additional information can be gleamed from the "slow-mo" view of catalyst activity. Benzene has been detected as a minor product in a high pressure study of vanadium oxide/alumina catalysts for butane dehydrogenation [36], can form via the hydrogenolysis of the secondary-secondary $\mathrm{C}-\mathrm{C}$ bond followed by oligomerization to benzene. Several authors have investigated zeolite based catalysts for the aromatisation of $n$ butane to benzene [41-43]. Shpiro et al [42] described the formation of aromatic compounds from $n$-butane over $\mathrm{Pt} / \mathrm{Ga}$ containing zeolites and Nguyen et al [43] combined kinetic and experimental results to determine the mechanistic steps. They suggest that the main route is through dehydrogenation to an alkene, followed by oligimerisation, cyclisation then dehydrogenation. These processes have also been described with regards to the coking mechanism of catalysts which is thought to proceed via the same steps [44].

At the same time, XP spectra of the V2 $\mathrm{p}_{3 / 2}$ core electron levels were measured under reaction conditions. Figure $9 \mathrm{a}$ shows the changes observed in the $\mathrm{V} 2 \mathrm{p}_{3 / 2}$ peak of the $8 \%$ V/alumina with varying reaction conditions. Under an oxygen atmosphere $(0.5 \mathrm{mbar}$ and $723 \mathrm{~K})$, one relatively sharp peak was observed at $517.2 \mathrm{eV}$, the binding energy of which corresponds well with that of $\mathrm{V}^{5+}$ [45]. Only a small shoulder is observed on the low binding energy side of the peak, which suggests that less than $4 \%$ reduced vanadium is remaining in the oxidized catalyst. The catalyst was then treated in hydrogen $(1 \mathrm{mbar}, 723 \mathrm{~K})$ and the contribution of reduced vanadium increased to around $30 \%$ of the $V 2 p_{3 / 2}$ peak (spectrum not shown). 

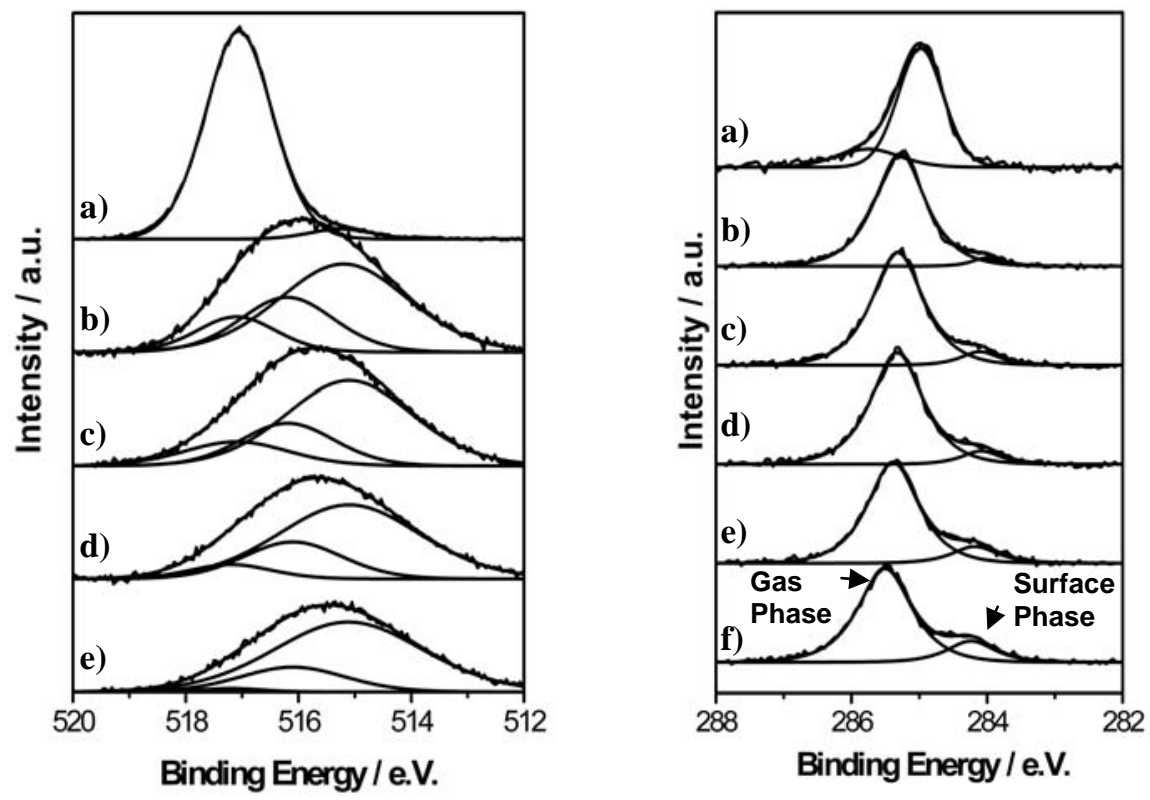

Fig. 9: (a): XP spectra of $V 2 p_{3 / 2}$ region during reaction of $n$-butane $(0.4$ mbar) over $8 \%$ V/alumina at $723 \mathrm{~K}$, in (a) 0.5 mbar oxygen and 0.4 mbar n-butane after (b) $53 \mathrm{~min}$, (c) $87 \mathrm{~min}$, (d) $129 \mathrm{~min}$ and (e) $186 \mathrm{~min}$.

(b): XPS of C1s region during reaction in n-butane (0.4 mbar, $673 \mathrm{~K}$ ) after (a) $60 \mathrm{~min}$, (b) $96 \mathrm{~min}$, (c) $114 \mathrm{~min}$, (d) $118 \mathrm{~min}$, (e) $134 \mathrm{~min}$ and (f) $174 \mathrm{~min}$ in the reaction mixture.

Under dehydrogenation conditions, there is a distinct broadening of the $\mathrm{V} 2 \mathrm{p}_{3 / 2}$ peak and a shift to lower binding energy (figure 9a) due to reduction of $\mathrm{V}$ under reaction conditions. The broadening of the components assigned to the oxidation states, which are commonly observed for $\mathrm{V}_{2} \mathrm{O}_{3}$ and $\mathrm{V}_{2} \mathrm{O}_{4}$ is due to the increased number of multiplet configurations available in the corresponding final states. The position of the peak in the final spectrum is $515.5 \mathrm{eV}$, which is in good agreement with the value given for $\mathrm{V}^{3+}$ [45]. It should be mentioned that fitting of the vanadium peak is non-trivial due to the broadening and varying binding energy calibration references that are used in literature (e.g. valence band onset or internal standard). The spectra shown in figure 9 are fitted with three components corresponding to formal oxidation states of 5,4 and 3+ with binding energies of 517.1-2, 516.1-2 and 515.1-2 eV, respectively. The authors do consider this method to be consistent across a range of vanadium containing materials. In addition to the broadening and shifting of the peak, there is also a decrease in intensity of the V $2 p$ feature compared to Al $2 p$ signal of the support. This suggests that either the vanadium is preferentially covered by carbon or that there is agglomeration of the vanadium oxide particles during reaction which leads to a decreased contribution from vanadium.

Furthermore, distinct changes were observed in the $\mathrm{C} 1 \mathrm{~s}$ region as shown in figure $9 \mathrm{~b}$. Originally only the gas phase carbon peak is present. However during the dehydrogenation reaction this peak shifts, due to a change in work function of the sample as V reduced and carbon was depos- ited on the surface [46]. As the reaction starts to deactivate the intensity of the surface component increases. This increase correlates with a maximum in formation of benzene. Hence the carbon accumulation may be due to retention of benzene by the catalyst.

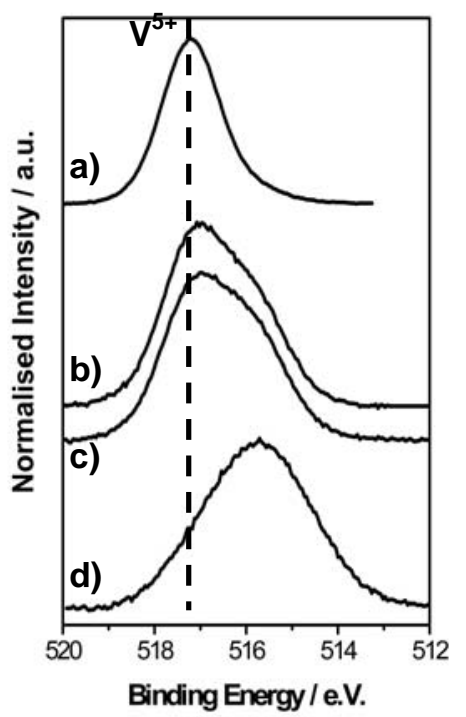

Fig. 10: Comparison of $\mathrm{V} 2 \mathrm{p}_{3 / 2}$ XPS of $3.5 \%$ V/alumina in (a) 0.5 mbar oxygen, (b) 0.4 mbar $2 \% \mathrm{O}_{2}$ in $n$-butane, (c) 0.4 mbar $1 \% \mathrm{O}_{2}$ in $n$-butane and (d) 0.4 mbar $n$-butane. 


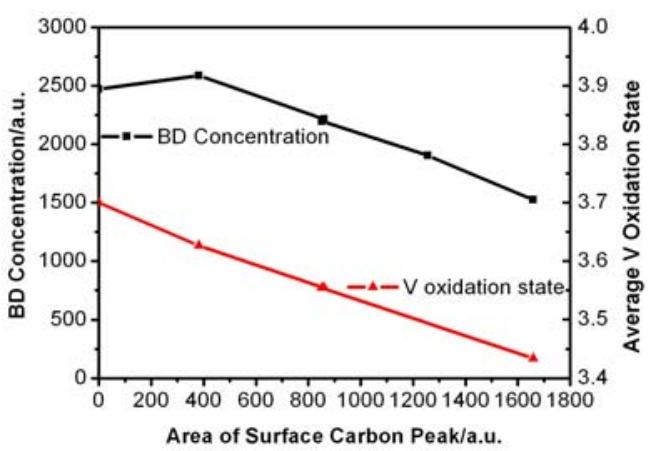

Fig. 11: Structure-activity link between surface carbon, activity and oxidation state.

By relating the area of the peak corresponding to surface carbon with the average formal oxidation state (as derived from peak fitting of the $\mathrm{V} 2 \mathrm{p}_{3 / 2}$ spectra (see figure 10) and the catalytic activity, a direct correlation can be observed between catalytic activity and vanadium surface electronic structure.

Figure 11 shows that the vanadium oxidation state decreases parallel with increasing surface carbon. However the formation of butene and butadiene is not immediately effected by the formation of carbon on the surface. Only when the reduction of vanadium and formation of carbon reaches a certain extent does the dehydrogenation activity begin to decrease. Hence, it can be postulated that the deactivation occurs via two steps. Immediately on introduction of $n$-butane, the oxidation state of vanadium is reduced, however it is not until after more than $60 \mathrm{~min}$ under reaction conditions that surface carbon is observed. Further retention of carbon (probably unsaturated hydrocarbons) requires multiple reduced vanadium sites, whereas their cumulative effect will result in catalyst deactivation.

As the catalyst deactivated carbon was formed on its surface during reaction, regeneration steps were used to determine the reversibility of carbon retention. After each regeneration (treatment in oxygen then hydrogen), the catalyst showed a higher activity towards the formation of butene and butadiene (as can be seen in figure 8). This was in agreement with Jackson et al [47] who investigated $\mathrm{V}_{\mathrm{x}} \mathrm{O}_{\mathrm{y}}$ /alumina catalysts at high pressure ( 1 bar) for $n$-butane dehydrogenation and observed an increase in activity on subsequent cycles. During our investigation, three reaction cycles were performed over the catalyst. After regeneration, the surface was free of carbon. Vanadium XPS (not shown) at the same point during each dehydrogenation reaction showed that there was a slight increase in the oxidation state of vanadium after repeated regeneration and dehydrogenation cycles. Hence the maintenance of less reduced $\mathrm{V}\left(\right.$ less $\mathrm{V}^{3+}$ ) correlates with increasing dehydrogenation activity.

As part of our in situ studies, a 3.5\% V/alumina catalyst was examined for the dehydrogenation of $n$-butane with and without 1-2\% oxygen co-feed. Unfortunately addition of oxygen increased the formation of oxygenated products, including low concentrations of furan and dihydrofuran. However one possible benefit was the maintenance of $\mathrm{V}^{5+}$ as shown in figure 10 and that carbon was not observed on the catalyst surface. Hence, through control of the oxygen content of the feed gas it may be possible to balance the oxidation state of vanadium necessary for activity while reducing the formation of side-products.

From our in situ investigations, it is clear that reduced vanadium is active in the dehydrogenation of $n$ butane and as shown in figure 11, however complete reduction to $\mathrm{V}^{3+}$ is not beneficial, as neighbouring $\mathrm{V}^{3+}$ sites will bond adsorbates of C-deposits too strongly. This is in agreement with the work of Harlin et al [36] who concluded that reduced vanadium was indeed active in the dehydrogenation reaction. By co-feeding oxygen, a higher oxidation state of vanadium is maintained. Hence the presence of $\mathrm{V}^{5+}$ prevents accumulation of carbon on the surface. This effect of reducing carbonaceous deposits by cofeeding oxygen has been observed over Pt/alumina catalysts [48]. In the case reported, oxygen had two purposes: to fill high energy adsorption sites, allowing products to desorb and to remove surface carbon, effectively cleaning the surface.

Measurement of the carbon K-edge in the soft x-ray adsorption range provides useful information about the nature of deposited carbon which is difficult to ascertain from other spectroscopic methods. As mentioned earlier, less than $3 \%$ elemental carbon (determined by XPS) was formed on the surface of the catalyst during the low pressure reaction. Hence, post-reaction evaluation was also made of samples which were deactivated during reaction with 1 bar $n$-butane at $873 \mathrm{~K}$ as shown in figure $12(\mathrm{a}-\mathrm{c}))$.

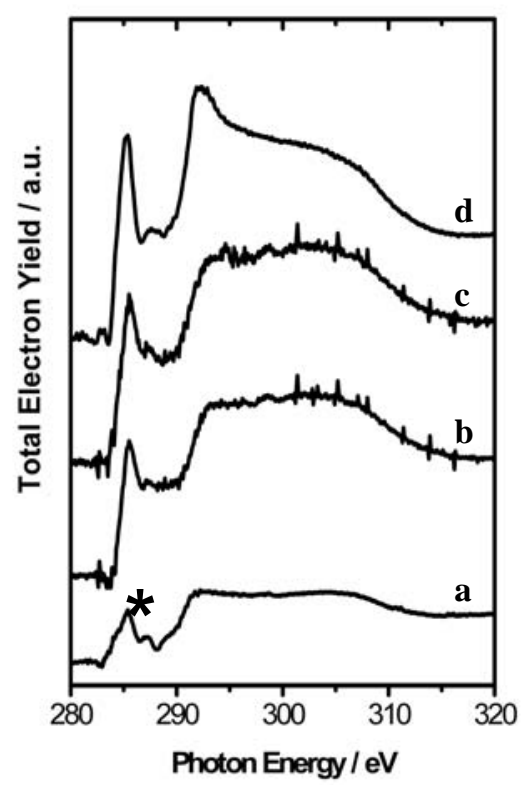

Fig. 12: Ex-situ post-reaction carbon K-edge NEXAFS of (a) $1 \%$ V/alumina, (b) $3.5 \%$ V/alumina and (c) $8 \%$ V/alumina deactivated during dehydrogenation of $n$-butane (1 bar) at $873 \mathrm{~K}$ and (d) graphite layer. 
Vanadium XPS shows that the catalyst is greatly reduced $(\mathrm{BE} \sim 515.9 \mathrm{eV})$. The main feature common to all of the carbon K-edge absorption spectra can be attributed to a $1 \mathrm{~s}$ to $\pi^{*}$ resonance due to the presence of unsaturated hydrocarbons. There were no distinct features in the $1 \mathrm{~s}$ to $\sigma^{*}$ region $(\sim 290-320 \mathrm{eV})$ which would indicate the formation of a well ordered form of carbon, such as in the case of highly ordered graphite [49]. The 3.5\% V/alumina and $8 \%$ V/alumina had similar K-edges, which corresponded to disordered carbon [50]. The 1\% V/alumina catalyst showed however additional features on the low energy side of the main $\mathrm{C} 1 \mathrm{~s}$ to $\pi^{*}$ transition. Although not common, similar features were observed by Kolczewski and coworkers [51] and by Schlögl and co-workers [52] while investigating the absorption spectrum of styrene and ethylbenzene. Hence, the unexplained features of the absorption spectrum for the $1 \%$ V/alumina may be due to the presence of a styrene-like compound. This fits well with findings of a UV-Raman study into the deactivation processes during butane dehydrogenation over $\mathrm{V}_{\mathrm{x}} \mathrm{O}_{\mathrm{y}} /$ alumina, which detected polystyrene like intermediates during deposition of carbon on the surface deactivation [53]. Since the styrenelike features were only observed on $1 \% \mathrm{~V}$, it is possible or that the initial vanadium phase of mainly monomeric and dimeric species has an effect on the carbon species deposited. Additionally, variation of the intensity around $287 \pm 1 \mathrm{eV}$ is related to the presence of $\mathrm{C}-\mathrm{H}$ bond orbitals [54]. Thus the nature of the carbon formed on the surface of the catalyst is affected by the catalyst loading and more likely the nature of vanadium oxide present i.e. isolated, polymeric and 3-D $\mathrm{V}_{2} \mathrm{O}_{5}$ crystallites. This structure dependency on the nature of coke formation has been observed previously [44].

Hence, by combining in-situ and ex-situ spectroscopic experiments, it was possible to gain a greater insight into the dehydrogenation of $n$-butane and the subsequent carbon deposition. On addition of oxygen to the feed, surface carbon was not observed, however there was an increase in the formation of side-products. The additional maintenance of the $\mathrm{V}^{5+}$ species suggests that maintaining a mixture of oxidation states is crucial to prevent deactivation, i.e. multiple neighbouring reduced sites provide absorption sites for hydrocarbons, most likely unsaturated, causing coking and desorption hinderance for reaction intermediates [47].

Hess et al. [58, 59] observed an additional feature in their XPS of $\mathrm{V}_{\mathrm{x}} \mathrm{O}_{\mathrm{y}} / \mathrm{SBA}-15$ samples, at even higher binding energy than expected for $\mathrm{V}^{5+}$. This was attributed to charging in the final state by the presence of small particles on an insulating support. Upon dehydration a dramatic change in the intensity ration of the two $\mathrm{V}^{5+}$ components was observed as a result of a substantial increase in the vanadia dispersion.

In situ XPS proved to be a useful tool for identifying changes in vanadium oxidation state and deposition of carbon under reaction conditions. In the case of the vanadium/alumina catalysts, the presence of carbon appeared to have a negative effect on the formation of primary dehy- drogenation products by blocking active sites required for catalysis.

The application of in situ XPS clearly demonstrated the dynamic character of the catalyst surface under changes of the reaction conditions. The formation a $\mathrm{Pd}-\mathrm{C}$ phase in the selective hydrogenation of pentyne and the formation of partly reduced $\mathrm{V}$ sites during the dehydrogenation of $\mathrm{n}$ butane were shown to be metastable. As soon as the gas feed was changed, the surface of the Pd and V catalysts changed.

\section{Summary and Outlook}

The examples presented in this contribution show, that the influence of $\mathrm{C}$ on the catalytic activity has a great variety. The formation of a carbon dissolved phase in $\mathrm{Pd}$ alters the electronic structure of the Pd surface. As shown in the 1-pentyne hydrogenation study, this phase disturbs the equilibrium between gas phase hydrogen and dissolved hydrogen, with strong influences on the selectivity. A very similar PdC phase was observed during the ethene oxidation over Pd. In this reaction the selectivity to $\mathrm{CO}$ is enhanced, when this special PdC phase is build up. In the case of the $n$-butane dehydrogenation the observed carbon deposit is correlated with deactivation of the $\mathrm{V}$ based catalyst. In this case the carbon atoms seem to block the active sites of the dehydrogenation reaction. Co-feed of oxygen reduces the coking and thus prevents deactivation. However, it promotes the formation of side-products.

These case studies highlight the power of in situ XPS for the characterization of catalysts. The ultimate surface and element sensitivity on the one hand and the possibility to vary the information depth on the other hand adds an extra quality to XPS when operated at the synchrotron. In addition, X-ray absorption spectra (XAS) can be taken at a synchrotron to sustain XPS results. XAS is especially useful to gain information about the geometric structure that is often hard to conclude from XPS results alone. This became obvious in the case of V-based catalysts where C-Kedge absorption spectra have been recorded to clarify the nature of carbon. The necessity to monitor changes in the gas phase simultaneously to the spectroscopic characterization was demonstrated. By doing so, a correlation between surface and subsurface species with the catalytic performance of the catalyst was obtained. It became obvious that in situ XPS, though still limited to a certain pressure range (a few mbar) can be applied under relevant conditions on relevant materials.

Obviously, it raises the question, if the pressure limit of in situ XPS might be enhanced further. In the following the physical boundaries of an XPS system based on a differentially pumped lens system will be discussed briefly.

Technically, pressures up to $100 \mathrm{mbar}$ and higher might be handled with a differentially pump electrostatic lens system. Certainly, the differential pumping needs to be organised in that way that no electric discharge can occur inside the lens system due to an improper local gas pres- 
sure/voltage combination. A challenging problem is to cope with the electron scattering within the vicinity of the $1^{\text {st }}$ aperture of the lens system (on both sides of the aperture). Obviously, the path length of electrons in the gas phase needs to be minimized; i.e. the sample has to be located as close as possible to the $1^{\text {st }}$ aperture of the pumping stages to reduce electron scattering. Due to the gas flow through the $1^{\text {st }}$ aperture and the resulting local pressure drop in the vicinity of the aperture, the aperture diameter needs to be made small if the sample is moved close to it. This requires an adaptation of the X-ray spot size on the sample to the size of the aperture. The electron source, i.e. the illuminated area, i.e. the X-ray spot size should not exceed the aperture size to have a high acceptance of the released photoelectrons. The creation of small X-ray spots in the $\mu \mathrm{m}$ range is feasible at modern $3^{\text {rd }}$ generation synchrotron radiation sources like BESSY. The advent of $4^{\text {th }}$ generation sources, i.e. free electron lasers (FEL) will make even more intense small spot X-ray sources available. Nevertheless, small X-ray spots with high intensity (i.e. high photon density) might cause severe problems regarding the stability of adsorbed species or the integrity of the catalyst material itself (especially of oxide surfaces). Catalytically active surfaces need to show a high dynamic flexibility and response on the ambient conditions thus these surfaces might be especially fragile. Although details of the mechanism of photon-induced damage (e.g. changes of the physical structure and topography, molecular and electronic structure, and atomic composition) are still under discussion, beam damage is known to be a severe problem in studying nonconducting materials, polymers and organic materials [60, 61].

It seems obvious that every system under investigation needs to be carefully checked for these effects. There might exist individual pressure limits from this point of view for each system under investigation. Thus, a flexible experimental set-up that can be adapted to the needs concerning aperture diameter and X-ray density seems beneficial. Hard X-ray photoelectron spectroscopy might circumvent partially this issue and there is also a reduced scattering of high energy electrons with the gas phase (i.e. higher pressures are possible) but there is a lack of ultimate surface sensitivity due to the increased kinetic energy of the photoelectrons. Furthermore, avoiding a gas discharge inside the lens system might be somehow problematic due to the higher voltages applied in case of an high kinetic energy electron spectrometer.

Nevertheless, further development in detector technology and higher acceptance and enhanced transmission of future electrostatic lens systems certainly will increase the pressure limit of in situ XPS.

Furthermore, it was demonstrated in this report that the study of more kinetically demanding catalytic reactions is extremely useful. To tackle this topic, it seems necessary to incorporate the requirements for an adequate chemical reaction environment into the design of spectroscopic cells in order to mimic relevant conditions. Obviously, not an easy task having in mind the classical layout of an UHV surface science electron spectroscopy experiment at a synchrotron source.

Beside the development of experimental techniques and equipment that allow for an advanced usage of modern electron spectroscopic techniques like in situ XPS, the access and handling of these stations needs to be improved to allow for a more general usage in the catalytic community. BESSY and the FHI recently installed a facility to tackle this problem. This facility named ISISS (innovative station for in situ spectroscopy) that started test operation in the beginning of 2007 should be described briefly in the following.

ISISS consists of 3 main parts: a): the in situ XPS endstation that was used to obtain the results described in this report, b) a state of the art soft X-ray beamline, and c) the installation of a permanent infrastructure on site for experiments with a chemical background. The soft X-ray beamline is optimized to deliver photons in the energy range of $80 \mathrm{eV}-2000 \mathrm{eV}$, thereby allowing XPS of all relevant core levels. Additionally, it is possible to perform Xray absorption measurements for a variety of important elements (e.g. K-edge of light elements like carbon, nitrogen, oxygen, L-edges of transition metals). Furthermore, the variation of photon energies over a reasonable extended energy range becomes feasible to perform depth profiling experiments as described in this report. Details of the optical layout of the beamline will be published elsewhere.

The availability of a permanent infrastructure on site for experiments with a chemical background is realised to be essential. In contrast to standard vacuum surface science experiments, in situ experiments require the installation of a complex gas feed and elaborated gas analytics to determine the conversion of the gas phase during the reaction. Hazardous substances (e.g. poisonous or flammable) can be used much more safely with a permanent installation. Thus, the in situ XPS end station is completely covered in a ventilated housing big enough to operate it at ISISS. Thereby, all hazardous substances are separated from other synchrotron users in the experimental hall. This approach allows the effective installation of safety sensors if required. Another area in this housing gives the opportunity for easy and more complex sample pre-treatment like calcinations, washing, drying pelletizing etc. Obviously, a non-permanent infrastructure is either not capable of making these kind of experiments possible or it will be less safe, much more time consuming and costly in the long run.

It is expected that this facility will encourage the usage of in situ XPS for characterisation of catalysts at BESSY in the future.

\section{Acknowledgement}

The authors gratefully acknowledge the BESSY staff for their continuous support during the experiments. Thomas Hansen is acknowledged for the TEM image of the alumina supported V catalyst. We thank the Deutsche Forschungsgemeinschaft (DFG) for the financial support 
through the Sonderforschungsbereich 546 and we do thank also EPRSC of the UK and Johnson Matthey plc for funding of the Athena Project.

\section{References}

1. Siegbahn K, Nordling C, Johansson G, Hedman J, Heden P F, Hamrin K, Gelius U, Bergmark T., Werme L O, Manne R and Baer Y 1969 ESCA applied to free molecules North-Holland Publishing Company

2. Joyner R W, Roberts M W and Yates K 1979 Surf. Sci. 87501

3. Ruppender H J, Grunze M, Kong C W and Wilmers 1990 M Surf. Interf. Anal. 15245

4. Kelly M A, Shek M L, Pianetta P, Gür T M and Beasley M R 2001 J. Vac. Sci. Technol. A 192127

5. Pantförder J, Pöllmann S, Zhu J F, Borgmann D, Denecke R and Steinrück H-P 2005 Rev. Sci. Instrum. 76 014102

6. Ogletree D F, Bluhm H, Lebedev G, Fadley C S, Hussain Z and Salmeron M 2002 Rev. Sci. Instrum. 733872

7. Bluhm H, Hävecker $M$, Ihmann $K$, Kleimenov E, Teschner D, Ogletree D F, Salmeron M, Knop-Gericke A and Schlögl R Rev. Sci. Intrum. To be submitted

8. Tanuma S, Powell C J and Penn D R 1994 Surf. Interface Anal. 21165

9. Yeh J J and Lindau I 1985 Atomic Data and Nuclear Data Tables 32 1-155

10. Himpsel F J, McFeely F R, Taleb-Ibrahimi A, Yarmoff J A, Hollinger G, 1988 Phys. Rev. B 38 6084-6096

11. Follath R and Senf F 1997 Nucl. Instr. and Meth. A 390 388-94

12. Senf F and Sawhney K J S 2001 Nucl. Instr. and Meth. A 467-68 466-69

13. Sawhney K J S, Senf F, Scheer M, Scheer F, Schäfers F, Bahrdt J, Gaupp A and Gudat W Nucl. Instr. and Meth. A 390 395-402

14. Unterberger W, Gabasch H, Hayek K and Klötzer B 2005 Catal. Lett. 104 1-8

15. Han Y F, Kumar D, Sivadinarayana C, Clearfield A and Goodman D W 2004 J. Catal. 94 131-134

16. Bowker M and Morgan C 2005 Catal. Lett. 9867

17. Gabasch H, Hayek K, Klötzer B, Knop-Gericke A and Schlögl R 2006 J. Phys. Chem. B 110 4947-4952

18. Juddanov I V, Neyman K M and Rösch N, 2004 Phys. Chem. Chem. Phys. 6 116-123

19. Rose M K, Borg A, Mitsui T, Ogletree D F and Salmeron M 2001 J. Chem. Phys. 11510927

20. Teschner D, Vass E, Hävecker M, Zafeiratos S, Schnörch P, Sauer H, Knop-Gericke A, Schlögl R, Chamam M, Wootsch A, Canning A S, Gamman J J, Jackson S D, McGregor J and Gladden L F $2006 \mathrm{~J}$. Catal. 24226

21. Chastain J (Ed.) 1992 Handbook of X-Ray Photoelectron Spectroscopy Perkin-Elmer

22. Teschner D, Pestryakov A, Kleimenov E, Hävecker M, Bluhm H, Sauer H, Knop-Gericke A and. Schlögl R 2005 J. Catal 230186

23. Teschner D, Pestryakov A, Kleimenov E, Hävecker M, Bluhm H, Sauer H, Knop-Gericke A and. Schlögl R 2005 J. Catal 230195
24. Daley S P, Utz A L, Trautmann T R and Ceyer S T 1994 J. Am. Chem. Soc. 1166001

25. Ceyer S T 2001 Acc. Chem. Res. 34737

26. Rupprechter G and Somorjai G A 1997 Catal. Lett 48 17

27. Doyle A M, Shaikhutdinov S, Jackson S D and Freund H-J 2003 Ang. Chem. 425240

28. Khan N A, Shaikhutdinov S and Freund H-J 2006 Catal. Lett. 108159

29. Haug K L, Burgi T, Trautman T R and Ceyer S T 1998 J. Am. Chem. Soc. 120885

30. Gabasch H, Kleimenov E, Teschner D, Zafeiratos S, Hävecker M, Knop-Gericke A, Schlögl R, Zemlyanov D, Aszalos-Kiss B, Hayek K and Klötzer B 2006 J. Catal. 242340

31. Surnev S, Sock M, Ramsey M G, Netzer F P, Wiklund M, Borg M and Andersen J M 2000 Surf. Sci. 470171

32. Nishijima M, Yoshinobu J, Sekitiani T and Onchi M J. 1989 Chem. Phys. 905114

33. Mimura N and Saito M 2000 Catalysis Today 55173

34. Shiau C-Y, Chen S, Tsai J C and Lin S I 2000 Applied Catalysis A: General 19895

35. Blasco T and López Nieto J M 1997 Applied Catalysis A: General 157, 117-142

36. Harlin M E, Niemi V M and Krause A O I 2000 Journal of Catalysis 195 67-78

37. López Nieto J M 2006 Topics in Catalysis 41, 3-15

38. López Nieto J M, Concepción P, Dejoz A, Knözinger H, Melo F and Vázquez M I 2000 Journal of Catalysis 189 147-157

39. Mamedov E A and Cortés Corberán V 1995 Applied Catalysis A: General 127 1-40

40. Volpe M, Tonetto G and de Lasa H 2004 Applied Catalysis A: General 272 69-78.

41. Kumar N and Lindfors L-E 1996 Applied Catalysis A: General 147 175-187

42. Shpiro E S, Shevchenko D P, Dmitriev R V, Tkachenko O P and Minachev K M 1994 Applied Catalysis A: General 107 165-180

43. Nguyen L H, Vazhnova T, Kolaczkowski S T and Luyanov D B 2006 Chemical Engineering Science 61 58815894

44. Wu Z and Stair P C 2006 Journal of Catalysis 237220 229

45. Bluhm H, Hävecker M, Knop-Gericke A, Kleimenov E, Schlögl R, Teschner D, Bukhtiyarov V I, Ogletree D F, Salmeron M 2004 Journal of Physical Chemistry B 108 14340-14347

46. Jackson S D, Rugmini S 2007 Journal of Catalysis 251, 59-68

47. McNamara J M, Jackson S D and Lennon D 2003 Catalysis Today $\mathbf{8 1}$ 583-587

48. Hitchcock A P and Mancini D C 1994 Journal of Electron Spectroscopy and Related Phenomena 67 1-132

49. Fayette L, Marcus B and Mermoux M 1998 Physical 
Review B 57 14123-14132

50. Kolczewski C, Puttner R, Martins M, Schlachter A S, Snell G, Sant'Anna M M, Herman K and Kaindl G 2006 Journal of Chemical Physics 124034302

51. Joseph Y, Wuhn M, Niklewski A, Ranke W, Weiss W, Wöll C, Schlögl R 2000 Physical Chemistry Chemical Physics 22 5314-5319

52. Jackson S D, Rugmini S, Stair P C and Wu Z 2006 Chemical Engineering Journal 120 127-132

53. Müller J-O, Su D S, Jentoft R E, Wild U and Schlögl R 2006 Environ. Sci. Technol. 40, 1231-1236

54. McGregor J 2007 in preparation

55. Hansen T W and McGregor J 2007 in preparation
56. Su D S, Maksimova N, Delgado J J, Keller N, Mestl G, Ledoux M J and Schlögl R 2005 Catalysis Today 102 110-114

57. Hess C, Schlögl R 2007 Chemical Physics Letters 432 139-145

58. Hess C, Tzolova-Müller G and Herbert R 2007 Journal of Physical Chemistry C 111 9471-9479

59. Thomas J H 1998 Beam Effects, Surface Topography and Depth Profiling in Surface Analysis p1, Ed by Czanderna A W, Madey T E and Powell C J, Plenum Press, New York, USA

60. Braga D and Grepioni 2000 Accounts Chem. Res. 33 601 